\title{
Panitumumab Regimen
}

National Cancer Institute

\section{Source}

National Cancer Institute. Panitumumab Regimen. NCI Thesaurus. Code C160104.

An immunotherapy regimen consisting of panitumumab that may be used in the treatment of wild-type RAS metastatic colorectal cancer. 